\title{
LOS PELIGROS DE UN ESTADO TOTALITARIO DE LA CIENCIA COMO MECANISMO REGULADOR DE LA CREACIÓN DE NUEVOS CONOCIMIENTOS
}

\section{THE DANGERS OF A TOTAL STATE OF SCIENCE AS A REGULATORY MECHANISM FOR THE CREATION OF NEW KNOWLEDGE}

Esteban Paniagua-Vega ${ }^{1}$

Recibido: 09.03.19

Aprobado: 30.04 .20

DOI: $10.15517 /$ isucr.v21i43.41974

\section{Resumen}

A partir de la primera oración del Manifiesto de Leyden se muestra las implicaciones de un Estado totalitario de la Ciencia, la imposición del dato como la ley de este estado, la exclusión de métodosotros y muchos mundos posibles de la investigación, así como el sometimiento y el control de la mente y del cuerpo del ser investigador, sometido a una serie de procesos para se considerado rigurosamente científico y como no anormal. Para ejemplificar esto, se concluye con cuatro ejemplos: la exigencia de referencias únicamente las obras más actuales, el requisito de redactar proyectos de tesis en diez o quince páginas, las formas estandarizadas de citar, tipo APA y la superposición de los datos y las rúbricas por encima de la evaluación de pares.

Palabras claves: Ciencia; Metodología; Investigación; Antipsiquiatría.

\begin{abstract}
From the first sentence of the Leyden Manifesto the implications of a totalitarian State of Science are shown, the imposition of the data as the law of this state, the exclusion of other methods and many possible worlds of research, as well as the submission and control of the mind and body of the investigating being, subjected to a series of processes to be considered rigorously scientific and not abnormal. To exemplify this, we conclude with four examples: the requirement of references only the most current works, the requirement to write thesis projects in ten or fifteen pages, the standardized forms of citing, APA type and the overlapping of the data and the rubrics above peer evaluation
\end{abstract}

Keywords: Science; Methodology; Research; Antipsychiatry.

\footnotetext{
${ }^{1}$ Docente Universidad de Costa Rica, Sede Occidente, San Ramón, Alajuela, Costa Rica Email: filosofo311@gmail.com
} 
Este artículo trata de llevar a sus últimas consecuencias la primera oración del Manifiesto de Leyden (2015), ya que tal exordio entrama un mundo conceptual que conduce peligrosamente a un totalitarismo en la ciencia. De ahí surge la necesidad de analizar detenidamente esta oración, trascender la epidermis de su significado y arribar a la médula de su sentido. Esta oración es: "Los datos sobre las actividades científicas están siendo cada vez más utilizados para gobernar la ciencia" (p. 1).

El empleo del verbo "gobernar" permite ordenar los contenidos de esta oración, a partir de un eje propiamente político. En este sentido, la ciencia podría ser vista como un Estado gobernado por una comunidad científica (Kuhn, 2004). A partir de sus propios criterios paradigmáticos, esta comunidad podría delimitar lo propiamente científico y separarlo, con una tajante navaja, de aquello que no lo es, tanto en el modo de plantear las proposiciones aceptadas como científicas, como en la exigencia del empleo de ciertos métodos oficiales o institucionalizados como propios de una disciplina científica (Foucault, 1992). El establecimiento de estos mecanismos de exclusión parte de estatutos axiomáticos, válidos o validados desde el punto de referencia epistemológico del que parte la comunidad científica para interpretar la realidad y conocer, en concordancia con su deseo de auto-conservarse como gobierno. Esta comunidad, para conservar su posición de privilegio, a través de su propio arcano de la ciencia (Schmitt, 1985), regula la búsqueda de anomalías, ejecutada por otras comunidades con otros criterios de ciencia o por el mero ejercicio del libre pensamiento y la investigación rigurosa, en la insaciable búsqueda de nuevos conocimientos (Feyerabend, 1986), sin importarle el status quo del gobierno del Estado de la Ciencia.

Inmerso en esta lucha de fuerzas, este gobierno de la ciencia no es más que un mundo posible (Leibniz, 1981), frente a muchos otros mundos posibles de la investigación. Sin embargo, este gobierno convierte al "dato" en ley del Estado. A partir de esta ley, no solamente gobierna sobre las actividades científicas, sino también, y en primera instancia, vigila y castiga las actividades referentes a la producción de nuevos conocimientos (Foucault, 2002); excluye, a partir de un tribunal de la razón (Hegel, 1991), del derecho de ciudadanía en territorio de la Ciencia y considera como delincuente o "extranjero indocumentado", todo conocimiento ubicado fuera de ese mundo posible e instituido constitucionalmente como la realidad de la Ciencia.

Mediante esta figura, un estado totalitario de la ciencia relativiza la oposición clásica entre

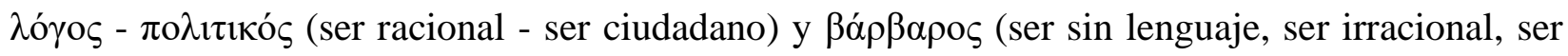


extranjero, ser esclavo) y determina una versión de ciencia, gobernada por los datos, frente a los demás mundos posibles de la investigación.

El dato en el Estado totalitario de la Ciencia no es ni siquiera entendido en el sentido del sinónimo de "hecho", sino como mero registro de información. Este sentido del dato se constituye en la ley del Estado de la Ciencia y como norma despliega todo un operativo biopolítico, a través del cual se institucionaliza la investigación tecnócrata e instrumental y se califica a un tipo de ser investigador, sometido a estos criterios, como un ser investigador normal, racionalmente científico, sano y sanitariamente a salvo de la delincuencia, del terrorismo y la indocumentación.

En contraste, quien emplea métodos-otros, en los cuales el dato y su registro seleccionado de información oficial no se encuentran en la cumbre de la montaña epistemológica y arroja luz sobre otros sectores del ser y formas de conocer, es considerado un ser investigador anormal, anómalo para la ciencia y toda la estructuración básica de un mundo totalitario y estático, establecido como real a través de la desaparición y el silenciamiento de cualquier otro mundo posible que pudiera obstaculizar su prolongación en la posición de privilegio del poder.

Estos otros mundos posibles son hijos de la especulación o el contacto directo con la realidad residual de este mundo, esculpido como Leviatán en nuestras mentes, con el cincel de los datos y el olvido de muchos otros mundos posibles, abordados por la esquizofrenia social de la producción de la producción de nuevos sentidos (Deleuze y Guatari, 1985). Mundos otros con aparatos interpretativos manados directamente del contacto con la sensación del hambre, la falta de luz, la olla de piedras cocidas por un general a la espera de sus cartas; mundos posibles emanados incluso de los datos, en el sentido de los hechos, pero no escritos, no registrados, no codificados como información o soporte de una investigación académica del Estado normal de la Ciencia.

Hechos muchas veces perversamente silenciados, como las realidades militares del mundo y la guerra civil social mundial (Saxe, 2006) que afrontamos todos los días. Hechos no presentados como datos de información por los medios masivos; hechos evidentes de la inutilización sistemática de nuestros cuerpos (Comité Invisible, 2007), codificados como máquinas deseantes y sujetos al orden de un residuo del capital. Mundos otros con marcos teóricos planteados desde las máquinas paranoicas y su continuo huir de la persecución de los cuerpos sin órganos que obstaculizan sus fluidos y regulan, a partir de códigos estructurados por el carácter más perverso del poder (Deleuze y Guatari, 1985). 
Tanto esos hechos como esos mundos posibles y métodos-otros representan para el Estado totalitario de la Ciencia un ser enfermo, insalubre, loco, anormal y si el ser investigador se atreve a pensarlos, deja de ser un ser investigador científico-conservador o productivo, reproductor de una realidad pre-dada como dato registrado como cuerpo sin órganos. En este caso, para el Estado totalitario de la Ciencia el problema es exclusivo del ser investigador como individuo, por no poder/querer ser normal, no alcanzar el triángulo edípico y por responder con burlona esquizofrenia al acoso estructurante que trata de normalizarle, nacionalizarle, documentarle de acuerdo a sus propios intereses.

El no seguir la norma, el dato o la ley como constitución política del Estado totalitario de la Ciencia, implica la necesidad de tomar antidepresivos, prozac, diazepam. El problema no es el Leviatán, siempre racional, políticamente correcto, militar y biomédicamente dispuesto. Lo que está mal no es la biopolitización de nuestras mentes y nuestros cuerpos, la contemplación acrítica de la evaluación de nuestros aprendizajes y producciones de conocimiento ni la regulación de la investigación hecha a partir de supuestos como la superposición de los datos. El hospital psiquiátrico ha venido a sustituir a la corte sueca, donde acabó sus días Descartes; está hecho para los seres deseantes y no para los cuerpos sin órganos que nos regulan con sus axiomas, cuerpos muertos, como el dato y el capital.

La superposición de los datos como criterios reguladores de las actividades científicas implica una biopolitización de la investigación, a partir de la cual los ciudadanos y las ciudadanas del Estado normal de la Ciencia, así como sus producciones cívicas, en el sentido más profundo de su currículo oculto, propiciarán el secuestro de lo real y su sustitución por una fábula (Nietzsche, 2001); una fábula sin color, sin sabor, sin olor, sin textura, sin sonido... Una fábula de números sin órganos, donde todo lo humano se ha perdido y lo anormal se encuentra silenciado, sometido, encerrado en campos de concentración adornados con luces, alambres navaja, tiendas y cámaras de seguridad (Virilio, 2001).

Un ser encuestador toca la puerta de un rancho, percibe el olor del hambre que le satura los pulmones y le hace un nudo en la garganta, mientras realiza una serie de anotaciones para una encuesta nacional de ingresos y gastos, con la alacena vacía. Lo humano del momento puede quedar en su vida, pero no por mucho tiempo o de lo contrario tendrá que tomar antidepresivos por no olvidar, por no someterse a la fábula continua. El ser encuestador no procesa los datos: los lleva desprovistos de carne y de hueso a otro departamento donde el trabajo de un escritorio nos recuerda 
a los cuerpos sin órganos y los resultados tecnócratas botand un trozo de pan en la basura, por no tener un estómago para digerirlo.

Otra figura de la fábula sale a la luz y finge que habla; al día siguiente repetirán las máquinas en los periódicos "x \% de personas vive en pobreza extrema" y esto lo lee nuestra mente con sus pulmones vacíos del sofocante olor al hambre o, peor aún, también con hambre. El periódico reproduce una pobreza muerta, sin órganos, un número, un dato; otra voz parla sandeces administrativas "hemos reducido la pobreza" y el gobierno del dato va más allá del bien y del mal: ahí yace el ser investigador, biopolitizado, obligado a tomar esos datos como sus referencias más rigurosas, para escribir artículos debidamente científicos; sometido a un vocabuliario rebuscado y traído a la ciencia de la disciplina militar y de la biología: el general ha tatuado en nuestros cerebros palabras bélicas para hablar de la pobreza y otros fenómenos sociales: erradicación, protección, extirpación, combate, crisis, derrota, etc. El ser científico de las disciplinas naturales también ha jugado su papel en nuestras amígdalas y lóbulos frontales: ha esculpido en el ser investigador parlantes que repiten a gritos palabras como "población", para referirse a la humanidad (Foucault, 2007).

La humanidad es en el Estado totalitario de la Ciencia una población, un "objeto de estudio", en la misma taxa que una población de líquenes, de flores, de murciélagos o de ratas. El ser investigador normal contempla a la humanidad en términos de población, de datos registrados de población y conforme a esto debe escribir, para que sus artículos tengan validez científica, ser ciudadano del Estado totalitario de la Ciencia y no ser un criminal quien no pasa de redactar un ensayo, sin valor como puntaje académico.

Las rúbricas como método y modelo de evaluación del conocimiento científico en las ciencias sociales y la educación, llegan a ser ese armamento nuclear de nuestra época, dirigido a la regulación del espacio, el contenido y la forma de la investigación y nos afecta, en tanto que cuerpos; haciendo surgir en ellos el alma o sujeto: el alma surge y se manifiesta a partir del castigo en el cuerpo del ser condenado (Foucault, 2002).

La rúbrica no solo implica el problema de definir el modo en que se mide, sino la cosificación de lo medido, la selección y conformación de un dispositivo a través del cual se arroja la luz sobre un sector específico del saber y muchos otros saberes quedan en la oscuridad. Con la rúbrica es más importante el instrumento que el conocimiento. Incluso quien produce conocimiento, pero no lo transmite de acuerdo a los criterios reguladores de la codificación de la 
rúbrica, podría hacérsenos ver como alguien quien no sabe nada de su temática, de su pasión, de su esfuerzo, de su vida; mientras que quien es estéril y no puede producir ni un solo matiz nuevo para brindarle algo distinto a la complejidad de la realidad, si sabe estilizar sus palabras, de acuerdo a los criterios de la rúbrica, puede ser considerado una eminencia y aplaudido por el oído y el ojo más superficial y menos exigente.

La selección de los criterios de las rúbricas no es tan inocente como la necesidad de elegir cuáles fotos colocamos en un álbum, cuando tenemos más espacio que fotografías. En la misma medida que cuando decidimos colocar dos imágenes juntas en un espacio específico del álbum familiar, constituimos una tercera imagen que dice algo de nosotros mismos (Lacan, 2009), esa tercera imagen de la selección y acomodo de los criterios de la rúbrica evidencia la codificación, la esterilidad de un poder instituido como norma de un ser que trata de estar fuera del tiempo, pero no deja de envejecer y le tiene una envidia disimulada a la energía más joven de la producción de la producción, capaz de generar nuevos sentidos, métodos y mundos posibles.

La selección canónica del Estado totalitario de la ciencia históricamente ha mutado y su establecimiento de una institucionalidad reguladora de los saberes ha dado paso a su versión más tecnócrata y burocrática, donde hay una superposición del registro a aquello que es registrado y, por tanto, de la forma al contenido. Forma de por sí misma caracterizada por ser una tercera imagen del poder, ir más allá y establecer ciertos parámetros axiomáticos como paredes, en medio de las cuales corre el riesgo de perderse la mente del monstruo.

Si el minotauro del ser investigador no puede hallar en sus propios adentros a aquel varón falogocéntrico, héroe, masculino, quien lo salve de pensar lo anormal y lo incorrecto para la norma de la comunidad de la ciencia, dándole muerte y convirtiéndolo en ese traidor de Teseo, entonces no dejará de ser monstruo. Paradójicamente, para dejar serlo e ignorar su laberinto, debe encontrar su libertad, encadenándose a asumir como única realidad real y posible los requisitos burocráticos y las ambigüedades de las rúbricas, completamente ajenas a sus discontinuidades creativas, leves reminiscencias de su vida como monstruo (no ha muerto en realidad, el Minotauro sigue escondido). Pero incluso presentándose como un completo Teseo, adoctrinado por el falo de los procedimientos a los que se somete voluntariamente, puede ser víctima de otro proceso dirigido por una mente angelical, como la de Kafka... ¿Cuál será la mentalidad del poder que tiende a esconderse detrás de la estandarización, el establecimiento de rúbricas y la tiranía de los datos? 
Nuevos mecanismos se imponen en la misma redacción y fungen como criterios de selección de los contenidos propiamente científicos. Entre estos mentaré algunos, quizá los que más me provocan. La exigencia de referenciar únicamente las obras más actuales es un criterio asumido acríticamente en algunas disciplinas y revistas, pero en el fondo constituye un ataque directo contra el abordaje y el estudio genealógico, así como contra la erudición, debido a que la genealogía puede mostrar, arrojar la luz sobre un sector del ser hasta entonces oscuro. La ciencia misma es ideología: la medicina no es tan perfecta como se nos presenta: en el siglo XVIII consideraba a la mujer como un hombre imperfecto, con un falo invertido hacia sus adentros (Foucault, 1998). El delirio positivista cae de su pedestal con el abordaje genealógico.

Otro de estos mecanismos es el requisito de la redacción de proyectos de tesis en diez o quince páginas, a espacio y medio, no obligando al ser estudiante a sintetizar, sino a excluir e ignorar los detalles, no periféricos, sino substanciales, así como la descripción crítica de los problemas investigados.

En un tercer lugar hallamos las formas estandarizadas de citar, como las propuestas o impuestas por APA, conforme a las cuales los pasadizos mentales ahogan al monstruo y tratan de convertirlo en un Teseo, ajeno a una concepción orgánica del conocimiento y amante de la aceptación acrítica y axiomática de la propiedad privada, incluso en el campo del saber.

Finalmente, la superposición de los datos y las rúbricas por encima de la evaluación de pares, lo cual constituye un ataque contra la generación de nuevos conocimientos, los cuales deben pasar por el embudo de la botella del formulario.

Esta codificación actual del conocimiento es paradójica. La creación de nuevos conocimientos implica movimientos, cambios, discontinuos. La rúbrica y el dato pretenden evitar ese tipo de anomalías y de ahí que a partir de ellos no sea lo novedoso lo medido por lo estándar, sino lo estándar el gendarme o regulador de lo novedoso, encadenado y sometido.

Presenciamos una superposición del dato al conocimiento y la anulación de muchos mundos posibles. Una supremacía de la técnica y una concepción biopolítica, sanitaria y racional sobre la humanidad, sus discontinuos, producciones y deseos.

\section{Bibliografía}

Comité Invisible (2007). La insurrección que llega. París: La fabrique Editions. 
Deleuze G. y Guatari, F. (1985). El Antiedipo. Capitalismo y esquizofrenia. Barcelona: Paidós. Feyerabend, P. (1986). Tratado contra el método. Esquema de una teoría anarquista del conocimiento. Madrid: Editorial Tecnos.

Foucault, M. (1992). El orden del discurso. Buenos Aires: Tusquets Editores.

Foucault, M. (1998). Historia de la sexualidad. Voluntad del Saber. Madrid: Siglo XXI.

Foucault, M (2002). Vigilar y Castigar. Buenos Aires: Siglo XXI.

Foucault, (2007). El nacimiento de la biopolítica. México: Fondo de Cultura Econócica

Gunnell, J. (2004a). Imagining the American Polity. Political Science and the Discourse of Democracy. Pennsylvania: The Pennsylvania State University.

Hegel, G. (1991). Fenomenología del Espíritu. Buenos Aires: Editorial Rescate.

Kuhn, T. (2004). La estructura de las revoluciones científicas. México: Fondo de Cultura Económica.

Lacan, J. (2009). Escritos I. Buenos Aires: Siglo XXI.

Leibniz, G. (1981). Monadología (Edición Trilingüe) (Trad.Julián Velarde). Oviedo: Ediciones Pentalfa.

Nietzsche, F. (2001). El crepúsculo de los ídolos o cómo se filosofa a martillazos. Madrid: Alianza Editorial.

Saxe, E. (2006). Colapso Mundial y Guerra. San José: Amo el Sur.

Schmitt, C. (1985). La dictadura. Madrid: Alianza Editorial.

Virilio, P. (2001). El procedimiento del silencio. Buenos Aires: Editorial Paidós. 